\title{
PINTURAS RUPESTRES EN UN ESPACIO FUNERARIO: EL CASO DEL SITIO CUEVA GALPÓN (NORESTE DE PATAGONIA)
}

\author{
NATALIA CARDEN* \& LUCIANO PRATES
}

\section{RESUMEN}

En este trabajo se presentan los primeros resultados del estudio del arte rupestre del sitio Cueva Galpón (noreste de la Patagonia, Argentina). Las evidencias arqueológicas halladas en la cueva están representadas por dos entierros humanos y pinturas rupestres rojas, negras y blancas. El análisis está orientado a evaluar la variabilidad interna del arte, plantear una secuencia de producción y discutir su contexto arqueológico. Los dos primeros objetivos se abordan mediante la caracterización formal de los motivos, el análisis de las superposiciones y la evaluación del estado de preservación. La contextualización se resuelve en las escalas intrasitio e intersitio, en la primera se evalúa el grado de relación entre las pinturas y los eventos mortuorios, y en la segunda se analizan las similitudes y diferencias con el arte rupestre de la región para discutir sus implicancias estilísticas, tecnológicas y cronológicas. Los resultados sugieren un piso cronológico de ca. 3.000 años para la ejecución de los motivos (lo cual coincide con las fechas obtenidas en uno de los entierros humanos) y un uso diacrónico de la cueva tanto para la producción de imágenes como para las inhumaciones. Se propone una probable interdependencia entre ambas prácticas y se discute el carácter inusual de esta asociación en el contexto arqueológico regional del Holoceno tardío.

PALABRAS CLAVE: pinturas rupestres, Norpatagonia, prácticas mortuorias, Holoceno tardío

$$
\begin{gathered}
\text { ROCK PAINTINGS IN A FUNERARY SPACE: } \\
\text { THE CASE OF CUEVA GALPÓN (NORDEASTERN PATAGONIA) }
\end{gathered}
$$

\footnotetext{
ABSTRACT

This paper introduces the first results from the study of the rock art evidence from Cueva Galpón (northeast Patagonia, Argentina). The archaeological evidence found in the cave is represented by two human burials and red, black and white rock paintings. It is intended to evaluate the internal variability of the rock art, to propose a production sequence and to discuss its archaeological context. The first two

Consejo Nacional de Investigaciones Científicas y Técnicas. Facultad de Ciencias Sociales, Universidad nacional del Centro de la Provincia de Buenos Aires. Av. Del Valle 5737. Olavarría. ncarden@soc.unicen.edu.ar

* Consejo Nacional de Investigaciones Científicas y Técnicas. División Arqueología, Facultad de Ciencias Naturales y Museo, Universidad Nacional de la Plata. Paseo del Bosque s/nº. La Plata. lprates@fcnym.unlp.edu.ar.
} 
objectives are approached through the formal characterization of motifs, the analysis of superimpositions and the evaluation of weathering. The contextualization is carried out through the intra-site and inter-site scales. The first one evaluates the relationships between the paintings and mortuary practices, and the second analyzes the similarities and differences with the regional rock art in order to discuss their stylistic, technologic and chronologic implications. The results suggest a chronology of ca. 3.000 years for the production of rock art (coincident with the dates obtained for one of the human burials) and a diachronic use of the cave both for the production of images and the inhumations. A possible interdependency between both kinds of practices is proposed, and this unusual association is discussed in the light of the regional information from the Late Holocene.

KEY WORDS: rock paintings, North Patagonia, mortuary practices, Late Holocene

\section{INTRODUCCIÓN}

Las investigaciones sobre el arte rupestre del norte de la Patagonia tienen una larga trayectoria $y$ han estado enfocadas principalmente en el sector andino o periandino de las provincias de Río Negro y Neuquén (Albornoz, 1996; Albornoz \& Cúneo, 2000; Boschín, 2009; Boschín \& Casamiquela, 2001; Bruch, 1904; Casamiquela, 1960, 1981; Ceballos \& Peronja, 1983; Crivelli, 2006; Crivelli \& Fernández, 1996; Crivelli et al. 1991, 1996; Fernández, 1979; Harrington, 1932; Llamazares, 1989; Pedersen, 1978; Podestá et al. 2008; Sánchez-Albornoz, 1958 a y b; Schobinger, 1956; Silveira, 1988-1989; Vignati, 1944, entre otros). Más hacia el Este la información disponible es mucho más escasa, en parte porque las investigaciones fueron discontinuadas y se reiniciaron muy recientemente -como en la meseta de Somuncura- (Blanco, 2015; Blanco et al. 2015; Gradin et al. 2003) o bien por la escasez o ausencia de representaciones debido a que no abundan o no existen en el paisaje soportes rocosos perdurables donde realizarlas -como ocurre en la mayor parte de las cuencas de los ríos Colorado y Negro, en la costa atlántica ${ }^{1}$ y en el área de planicies y bajos del centro y norte de la provincia de Río Negro.

En este trabajo se dan a conocer los primeros resultados del estudio de las manifestaciones rupestres del sitio Cueva Galpón, departamento

En este contexto de escasa información es importante mencionar el hallazgo de petroglifos en Punta Odriozola (costa oeste del Golfo San Matías, Río Negro) a una distancia de entre 50 y $150 \mathrm{~m}$ del mar y asociados a evidencias de adaptaciones litorales (concheros) datadas en ca. 3.000 de Valcheta, provincia de Río Negro (Fig. 1). Este sitio fue visitado por primera vez en diciembre de 2008 gracias a la información proporcionada y compañía de quién fuera en ese momento la directora del Museo de Valcheta, la Sra. M. I. Kopp, y de la actual directora de la misma institución, la Lic. Romina Rial. Aunque la zona había sido recorrida con anterioridad y se habían dado a conocer motivos pintados localizados a pocos kilómetros en el sitio Rinconada Catriel (Gradin et al. 2003), no existían hasta ahora referencias publicadas sobre Cueva Galpón.

En este trabajo se estudian las pinturas del sitio con el objetivo de evaluar su variabilidad interna y plantear una secuencia de producción de arte rupestre para la cueva. Además, se pretende analizar el contexto arqueológico del arte en las escalas intrasitio e intersitio. En la primera escala se evalúa la posible relación entre las manifestaciones rupestres y el resto de las evidencias arqueológicas recuperadas, correspondientes a entierros humanos. En la segunda escala se buscan similitudes y diferencias con el arte rupestre descripto para la región a fin de discutir sus implicancias estilísticas, tecnológicas y cronológicas, y se discute la información norpatagónica referida a cuevas o aleros con entierros humanos y arte rupestre. El estudio busca, de este modo, aportar elementos para entender el rol del sitio en el marco de la dinámica social del Holoceno tardío.

años AP (Carden \& Borella, 2015; Borella et al. 2015). Esta localización resulta novedosa si se tiene en cuenta que el único sitio con arte rupestre que dista menos de $40 \mathrm{~km}$ de la costa atlántica es Cañadón Encerrado, ubicado a 12 km de Punta Gaviotas, Chubut (Gómez-Otero \& Vallejo, 1996). 


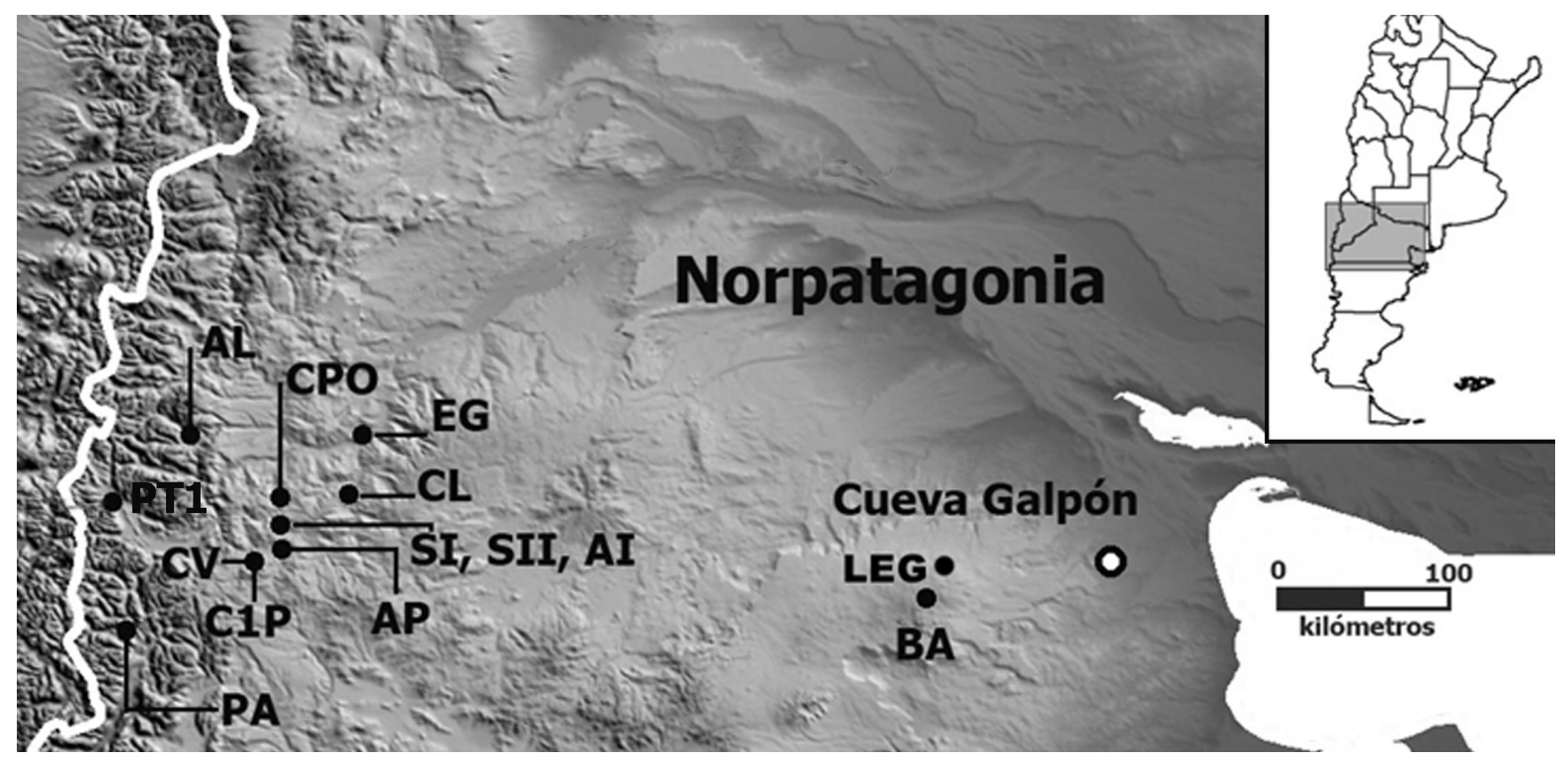

Fig. 1. Sitios mencionados en el texto con entierros humanos y arte rupestre: EG=Epullán Grande, CPO=Casa de Piedra de Ortega, PT1=Puerto Tranquilo 1, SII=Sarita II, C1P=Cueva 1 del río Pichileufú, CV=Cueva Visconti, PA=Población Anticura. Algunos sitios de la región con motivos rupestres similares a los de Cueva Galpón: AL=Alero Lariviére (Silveira, 1988-89), $\mathrm{CV}=$ Cueva Visconti (Ceballos \& Peronja, 1983), CL=Cueva Loncomán, SI=Sarita 1, AI=Alonso I, AP=Abrigo Pilcaniyeu (Boschín, 2009), BA=Bardas de Antonio, LEG=Laguna El Ganso (Blanco et al. 2015).

\section{DESCRIPCIÓN GENERAL Y CONTEXTO DEL SITIO}

Cueva Galpón se encuentra en el área Este de Norpatagonia, en la Sierra de Pailemán (4109'30's, 6547'30''W, 430 msnm). Esta formación integra el Complejo Plutónico Pailemán, al noreste del Macizo Norpatagónico, y está constituida principalmente por vulcanitas de edad jurásica (Busteros et al. 1998; Giacosa, 1993). El sitio está ubicado $15 \mathrm{~km}$ al este de las estribaciones orientales de la Meseta de Somuncura y $54 \mathrm{~km}$ al oeste del litoral atlántico. Fitogeográficamente, el área corresponde al Monte Austral, caracterizado por el predominio de una cobertura arbustiva xerófita (sensu León et al. 1998), y está comprendida dentro de la Diagonal Árida Sudamericana, donde el clima es templado árido, con precipitaciones cercanas a los $200 \mathrm{~mm}$ anuales (León et al. 1998; Paruelo et al. 1998).

La cueva tiene unos $45 \mathrm{~m}$ de frente y una profundidad máxima -medida entre la pared del fondo y la línea de goteo- de 10,5 m (Fig. 2). Está orientada al Este y, debido a que a pocos metros del frente (ca. 15) se eleva un frente rocoso casi vertical de unos $20 \mathrm{~m}$ de altura, el abrigo es muy poco visible desde los alrededores y no recibe prácticamente rayos solares directos. Desde el interior sólo se tiene dominio visual del sector de planicies arbustivas que se abre hacia el noreste, desde el cual se puede acceder a la cueva fácilmente. La fuente permanente de agua dulce más cercana al sitio es el arroyo Pailemán, ubicado ca. 12 km hacia el Oeste.

La mayor parte de la cueva presenta relleno sedimentario cuya potencia aumenta desde el fondo hacia el frente del abrigo, hasta alcanzar un máximo de $63 \mathrm{~cm}$ cerca de la línea de goteo sin contar la capa de guano. Debajo de la capa de guano de ovinos de ca. $55 \mathrm{~cm}$ de espesor promedio, la columna estratigráfica es homogénea y está integrada por una matriz de arenas grises muy finas de origen eólico, y un alto contenido de clastos procedentes del diaclasamiento y desprendimiento de la roca de caja. El sector central del abrigo está ocupado por un gran bloque de roca desprendido del techo.

Durante los primeros trabajos de campo realizados en el sitio, y a poco de comenzar con la observación general de las pinturas rupestres, se hallaron varios restos óseos humanos en el sector más profundo de la cueva. Estos materiales fueron 
Fig. 2. Vista de Cueva Galpón: I-III: sectores con arte rupestre, 1-8: motivos y conjuntos de arte rupestre, i-ii: contextos mortuorios 1 y 2.

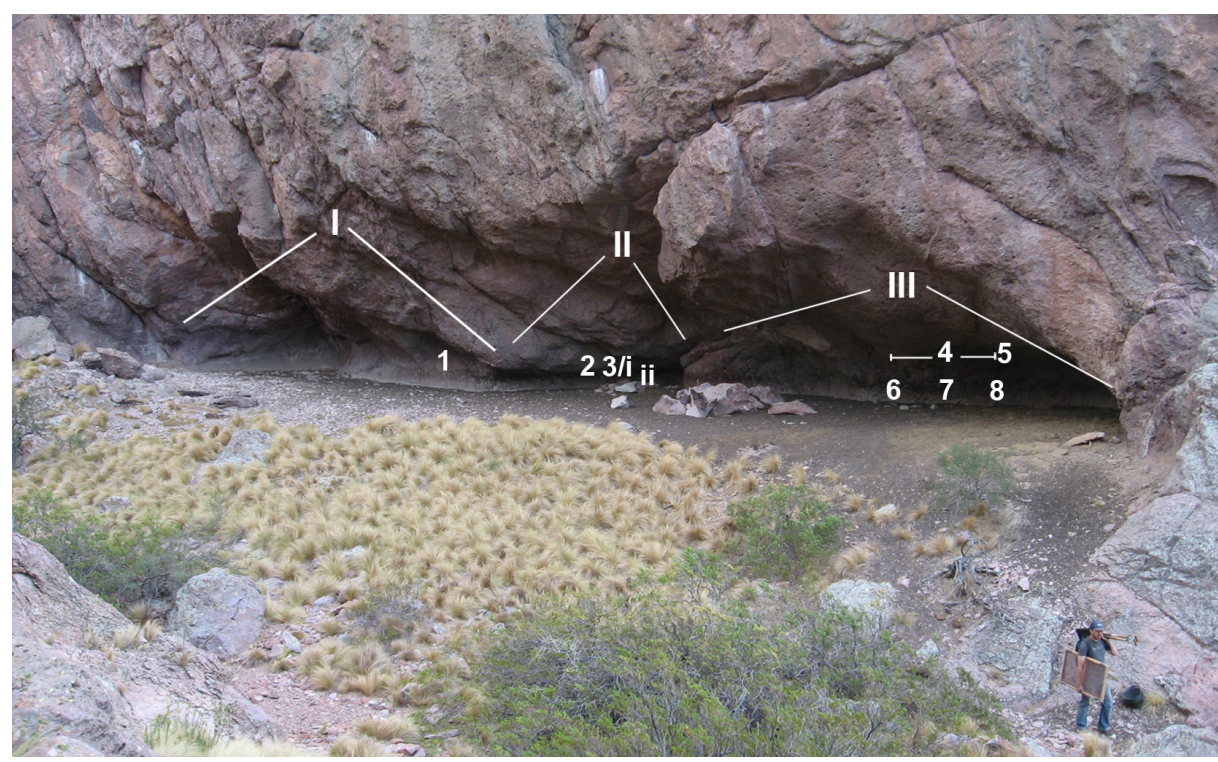

descubiertos fortuitamente luego de remover la capa de guano que cubría uno de los motivos pintados y, debido a que presentaban una marcada perturbación por el pisoteo de los animales, se decidió programar una excavación de rescate. El conjunto mortuorio, que se encuentra en proceso de estudio, está conformado al menos por dos contextos diferentes con los elementos óseos muy desarticulados y fragmentados (Serna, 2014). El estado de preservación y la proximidad entre ambos, sin embargo, no permitió aún diferenciarlos de manera completa.

El primer contexto mortuorio está conformado por una pila muy densa de huesos carbonizados, calcinados y altamente fragmentados (NMI=9, Serna, 2014) que se encontraba justo debajo de un conjunto de pinturas rupestres; estas últimas estaban tapadas por la capa de guano (Fig. 3). En asociación con el contexto mortuorio 1 se recuperaron restos de textiles, artefactos líticos (bolas de boleadora y artefactos de molienda discoidales), una pieza de cobre, valvas de moluscos y un pan de pigmento de color rojo oscuro de $920 \mathrm{~g}$ de peso (Prates et al. 2011). Las muestras de restos humanos enviadas a fechar no tenían colágeno suficiente para la aplicación del método radiocarbónico.

El segundo contexto mortuorio también se encontraba asociado espacialmente con el panel pintado pero algo más distanciado que el primero. Está integrado por huesos humanos más dispersos y menos fragmentados (NMI=3), sin evidencias tan marcadas de termoalteración, y asociados a camas de gramíneas fijadas con ramas, cordeles vegetales y un probable intermediario de proyectil de caña coligüe. A partir de un fragmento óseo humano y de un trozo de madera se obtuvieron dos edades radiocarbónicas de 3.314 \pm 51 (AA91544) y 3.264 \pm 38 (AA91543) años AP, respectivamente.

Además de la excavación de los entierros humanos y a fin de determinar la presencia de otro tipo de materiales arqueológicos en estratigrafía, se realizaron dos trincheras. Una fue excavada perpendicularmente a la línea de goteo en el sector III, desde la pared del fondo hasta el exterior y siempre alcanzando la roca de base. La segunda, en forma de T (de 3,5 x 3 m), se excavó entre el área de excavación y la línea de goteo. Mediante estos sondeos no se registraron materiales arqueológicos y tampoco se hallaron evidencias culturales en superficie.

\section{ASPECTOS TEÓRICO-METODOLÓGICOS}

La ausencia de actividades domésticas en Cueva Galpón sugiere que el sitio fue utilizado principal o exclusivamente para fines inhumatorios y de producción de imágenes rupestres. El lugar expresa, de este modo, una fuerte impronta y anclaje en las esferas simbólicas e ideológicas del comportamiento y, al mismo tiempo, una aparente exclusión de aquellas más conectadas con la subsistencia. Ambos tipos de evidencias señalan el uso persistente de la 
cueva para propósitos rituales, entendiendo que éstos son (...) sistemas codificados de prácticas (...) que implican la puesta en juego del cuerpo y cierta relación con lo sagrado (Maisonneuve, 2005, p. 12). Las prácticas rituales son "prescriptivas" porque conforman un modo especial de comunicación a partir de contenidos altamente formalizados que, aunque puedan estar discutidos, poseen mucha fuerza y admiten poca variación a lo largo del tiempo. A pesar de que el tiempo ritual es más conservador que el tiempo real, esto no niega el cambio ni el dinamismo de los significados, que se refieren a los aspectos "performativos" de los rituales (Bradley, 1991; Carden, 2013; Ross \& Davidson, 2006; Whitley, 2010).

Los sectores con arte rupestre de la cueva se definieron de izquierda a derecha sobre la base de discontinuidades en la presencia de motivos (más de cuatro metros sin pinturas) y de cambios marcados en la orientación del soporte rocoso. Se delimitaron motivos aislados y conjuntos dentro de dichos sectores (en sentido izquierda-derecha $y$ arriba-abajo) a partir de criterios formales, técnicos y espaciales. Un motivo se entiende como una unidad artística de ejecución y motivación, que puede ser simple o compuesto según esté conformado por uno o más elementos (Gradin, 1978). Cada conjunto se caracteriza por la presencia de motivos (simples y/o compuestos) que se vinculan por sus colores, técnicas y estado de preservación, y conforman de este modo un plan compositivo particular (Gradin, 1978). Aunque en general un conjunto implica sincronía en la ejecución de los motivos que lo componen, es posible que nuevos motivos se integren con posterioridad, lo cual determina el carácter "aditivo" de las manifestaciones rupestres (sensu Aschero, 1996). Esta particularidad inherente al arte rupestre permite definirlo como una "obra abierta", siempre sujeta a reutilizaciones y resignificaciones (Tilley, 1991; Troncoso, 2008). Los usos posteriores del arte rupestre pueden dejar correlatos materiales tales como el mantenimiento, yuxtaposición, superposición o supresión de imágenes (Martel et al. 2012; Pastor, 2012; Troncoso, 2008), o la presencia de objetos

2 La grasa lanar es una sustancia segregada por las glándulas sebáceas de los ovinos que, debido al roce de los animales contra las paredes de las cuevas cuando las utilizan como refugio, forma una impregnación oscura que fueron depositados en estrecha proximidad a los paneles con arte (Cáceres \& Berenguer, 1996; Whitley et al. 1999).

Para la clasificación de los motivos se tuvieron en cuenta la forma, el color, el tamaño, la preservación y los usos de los accidentes naturales del soporte (Carden, 2008; Hernández Llosas, 1985). Se consideraron, además, las superposiciones, el emplazamiento y el campo visual (sensu Aschero, 1988).

Con respecto a la preservación de las pinturas se definieron tres estados:

- bueno: las pinturas no presentan deterioro y los motivos pueden distinguirse con facilidad. Aunque los colores pueden estar algo atenuados, exhiben tonalidades fuertes y contrastes marcados con el soporte.

- regular: las pinturas se encuentran desvaídas o en proceso leve de exfoliación sin que ello constituya un obstáculo para la distinción de los motivos,

- malo: las pinturas presentan un grado de deterioro severo y los motivos no pueden distinguirse con facilidad, sea porque están muy desvaídas, porque se han exfoliado intensamente, o porque se encuentran cubiertas por grasa lanar².

En la clasificación morfológica las categorías de motivos fueron definidas a partir de sus semejanzas con elementos del mundo natural (biomorfos) o de sus formas geométricas (Gradin, 1978). En el último caso, los motivos se distinguen principalmente sobre la base de sus dimensiones y del tratamiento de la forma. De este modo, las categorías son las siguientes:

- Biomorfos: zoomorfos (pisadas), antropomorfos y fitomorfos.

- Puntos: pueden presentarse aislados, agrupados, alineados (en líneas simples o paralelas) o conformando figuras circulares.

- Trazos: líneas rectas o curvas cuya longitud es menor a $10 \mathrm{~cm}$, que se presentan aisladas,

en forma de banda horizontal (de unos $40 \mathrm{~cm}$ de ancho). Cuando estas impregnaciones cubren las pinturas rupestres es muy difícil distinguir los motivos. 
Tabla 1. Estado de preservación de los motivos por color

\begin{tabular}{|lcccccccc|}
\hline Preservación & blanco & $\%$ & negro & $\%$ & negro/rojo & $\%$ & rojo & $\%$ \\
\hline buena & 12 & $32 \%$ & 10 & $19 \%$ & 10 & $67 \%$ & 1 & $2 \%$ \\
mala & 1 & $3 \%$ & 6 & $11 \%$ & 0 & $0 \%$ & 30 & $64 \%$ \\
regular & 25 & $66 \%$ & 38 & $70 \%$ & 5 & $33 \%$ & 16 & $34 \%$ \\
\hline Totales & 38 & 100 & 54 & 100 & 15 & 100 & 47 & 100 \\
\hline
\end{tabular}

agrupadas sin una forma definida, alineadas en forma paralela o más irregularmente.

- Líneas: su longitud es mayor o igual a 10 $\mathrm{cm}$, pueden ser simples (rectas o curvas), en zigzag, paralelas, perpendiculares (en " $\mathrm{T}$ ", "peiniformes"), en "U", o lobuladas.

- Figuras: superficies delimitadas por líneas de trazo continuo, pueden ser rectilíneas (cuadrangulares, rectangulares) o curvilíneas (circulares, ovaladas) de tratamiento lineal o de cuerpo lleno.

En el análisis se consideraron, además, las superficies pintadas (sectores del soporte pintados homogéneamente sin configurar formas específicas) y motivos indeterminados (restos de pintura cuya forma no se puede distinguir debido a su estado de preservación malo).

\section{RESULTADOS}

En el sitio se identificaron 154 motivos rupestres monócromos (rojo, negro y blanco) y bícromos (rojo y negro). Éstos se encuentran sobre la pared del fondo de la cueva, que no recibe la luz directa del sol debido a su orientación y al reparo conferido por el abrigo. Aunque el soporte es en términos generales de textura irregular, las pinturas se encuentran en los sectores más homogéneos.

La preservación de más de la mitad de los motivos de Cueva Galpón $(n=84)$ es regular; les siguen en abundancia los motivos mal preservados $(n=37)$ y los bien preservados $(n=33)$. Las pinturas rojas presentan una preservación predominantemente mala, con motivos muy desvaídos e incompletos cuyas formas suelen ser difíciles de discernir. La preservación del negro es mayormente regular, aunque los motivos pueden ser observados sin dificultad a diferencia de lo que sucede con los rojos. Si bien el blanco también presenta un alto porcentaje de motivos con preservación regular, la cantidad de pinturas en buen estado supera a la de los demás colores (Tabla 1).

Además de los factores naturales que afectan la preservación de las pinturas, se registraron distintas inscripciones y marcas antrópicas (grafitis). Estos fueron realizadas con tiza sobre y entre los motivos en los sectores más altos de la pared rocosa, y mediante incisión a modo de rayado sobre uno de los conjuntos $\left(n^{\circ} 6\right)$.

\section{Identificación de los motivos}

Entre los 154 motivos registrados se identificaron 135; los 19 restantes corresponden a formas indeterminadas. Los motivos identificados son mayoritariamente líneas ( $n=39,29 \%)$, que abarcan una amplia diversidad de formas (Tabla 2). Les siguen las figuras ( $n=37,27 \%$ ), que incluyen una menor diversidad de subtipos entre los cuales predominan las formas circulares (lineales y de cuerpo lleno). Estos motivos son los más numerosos del sitio (Tabla 2 y Fig. 4). Los trazos abarcan el 19\% de la muestra $(n=25)$ y se observan principalmente dispuestos en forma irregular con orientación vertical. Entre los motivos biomorfos ( $n=14,10 \%)$ predominan los zoomorfos, que se manifiestan en forma de huellas (de guanaco, ave, felino y cávido), seguidos por los fitomorfos (con forma de hoja o tallo ramificado) y los antropomorfos muy esquemáticos (Tabla 2). Los puntos ( $n=14,10 \%)$ aparecen conformando formas circulares o líneas (simples y paralelas). Todas las superficies pintadas $(n=6,4 \%)$ son de color rojo y presentan motivos superpuestos, con excepción de un caso donde sólo se observa un área pintada de rojo de 0,36 $\mathrm{m}^{2}$.

$\mathrm{Si}$ se consideran todos los subtipos de motivos definidos para Cueva Galpón $(n=22)$, predominan las figuras curvilíneas -circulares y ovaladas- ( $n=34,22 \%)$. Los demás subtipos, con 
Tabla 2. Frecuencias de motivos por sector y color. B: blanco, R: rojo, N: negro, N/R: negro y rojo.

\begin{tabular}{|c|c|c|c|c|c|c|c|c|c|c|c|c|c|c|c|}
\hline \multirow{3}{*}{$\begin{array}{l}\text { Sector } \\
\text { Motivo o conjunto } \\
\text { Color }\end{array}$} & \multirow{3}{*}{$\begin{array}{l}1 \\
1 \\
\mathrm{~B}\end{array}$} & \multicolumn{4}{|c|}{2} & \multicolumn{9}{|c|}{3} & \multirow[b]{2}{*}{ Total } \\
\hline & & \multirow{2}{*}{$\begin{array}{l}2 \\
R\end{array}$} & \multicolumn{3}{|c|}{3} & \multicolumn{3}{|c|}{4} & \multirow{2}{*}{$\begin{array}{l}5 \\
\mathrm{R}\end{array}$} & \multicolumn{2}{|c|}{6} & \multicolumn{2}{|c|}{7} & \multirow{2}{*}{$\begin{array}{l}8 \\
\text { B }\end{array}$} & \\
\hline & & & $\mathrm{R}$ & $\mathrm{N}$ & $\mathrm{N} / \mathrm{R}$ & $\mathrm{R}$ & $\mathrm{N} / \mathrm{R}$ & B & & $\mathrm{R}$ & $\mathrm{N}$ & $\mathrm{N}$ & $\mathrm{R}$ & & \\
\hline pisadas de ave & 1 & 0 & 0 & 0 & 0 & 0 & 0 & 1 & 0 & 0 & 0 & 0 & 0 & 0 & 2 \\
\hline pisadas de felino & 0 & 0 & 0 & 0 & 0 & 0 & 0 & 0 & 0 & 0 & 0 & 2 & 0 & 0 & 2 \\
\hline pisadas de guanaco & 0 & 0 & 0 & 0 & 0 & 0 & 0 & 0 & 0 & 5 & 1 & 0 & 0 & 0 & 6 \\
\hline pisadas de cánido & 0 & 0 & 0 & 0 & 0 & 0 & 0 & 0 & 1 & 0 & 0 & 0 & 0 & 0 & 1 \\
\hline antropomorfo & 0 & 0 & 0 & 0 & 0 & 0 & 0 & 1 & 0 & 0 & 0 & 0 & 0 & 0 & 1 \\
\hline fitomorfo & 0 & 0 & 0 & 0 & 0 & 0 & 0 & 2 & 0 & 0 & 0 & 0 & 0 & 0 & 2 \\
\hline Biomorfos & 1 & 0 & 0 & 0 & 0 & 0 & 0 & 4 & 1 & 5 & 1 & 2 & 0 & 0 & 14 \\
\hline agrupados & 0 & 0 & 1 & 0 & 0 & 0 & 0 & 0 & 0 & 0 & 0 & 0 & 0 & 0 & 1 \\
\hline alineados & 0 & 0 & 0 & 2 & 0 & 0 & 0 & 2 & 1 & 0 & 1 & 0 & 0 & 0 & 6 \\
\hline en figuras & 0 & 0 & 0 & 6 & 0 & 0 & 0 & 0 & 0 & 1 & 0 & 0 & 0 & 0 & 7 \\
\hline Puntos & 0 & 0 & 1 & 8 & 0 & 0 & 0 & 2 & 1 & 1 & 1 & 0 & 0 & 0 & 14 \\
\hline aislados o en conjunto & 0 & 0 & 0 & 2 & 0 & 0 & 0 & 1 & 0 & 0 & 1 & 0 & 0 & 0 & 4 \\
\hline alineados regularmente & 0 & 0 & 0 & 1 & 0 & 3 & 0 & 0 & 1 & 0 & 0 & 1 & 0 & 0 & 6 \\
\hline alineados irregularmente & 0 & 0 & 0 & 0 & 0 & 0 & 0 & 0 & 0 & 11 & 4 & 0 & 0 & 0 & 15 \\
\hline Trazos & 0 & 0 & 0 & 3 & 0 & 3 & 0 & 1 & 1 & 11 & 5 & 1 & 0 & 0 & 25 \\
\hline simples & 0 & 0 & 1 & 1 & 0 & 0 & 0 & 1 & 2 & 1 & 1 & 2 & 0 & 5 & 14 \\
\hline en zigzag & 0 & 0 & 0 & 0 & 0 & 0 & 0 & 2 & 0 & 0 & 0 & 0 & 0 & 0 & 2 \\
\hline perpendiculares & 0 & 0 & 0 & 0 & 0 & 0 & 0 & 2 & 1 & 0 & 0 & 0 & 0 & 1 & 4 \\
\hline en $\mathrm{U}$ & 0 & 0 & 0 & 0 & 0 & 1 & 0 & 6 & 0 & 0 & 0 & 0 & 0 & 1 & 8 \\
\hline paralelas & 0 & 0 & 0 & 1 & 0 & 0 & 0 & 2 & 0 & 0 & 0 & 3 & 0 & 4 & 10 \\
\hline lobuladas & 0 & 0 & 0 & 0 & 0 & 0 & 0 & 0 & 1 & 0 & 0 & 0 & 0 & 0 & 1 \\
\hline Líneas & 0 & 0 & 1 & 2 & 0 & 1 & 0 & 13 & 4 & 1 & 1 & 5 & 0 & 11 & 39 \\
\hline curvilíneas & 0 & 0 & 0 & 11 & 14 & 6 & 0 & 1 & 1 & 0 & 0 & 0 & 0 & 1 & 34 \\
\hline rectilíneas & 0 & 0 & 0 & 0 & 0 & 1 & 0 & 2 & 0 & 0 & 0 & 0 & 0 & 0 & 3 \\
\hline Figuras & 0 & 0 & 0 & 11 & 14 & 7 & 0 & 3 & 1 & 0 & 0 & 0 & 0 & 1 & 37 \\
\hline superficie pintada & 0 & 1 & 4 & 0 & 0 & 0 & 0 & 0 & 0 & 0 & 0 & 0 & 1 & 0 & 6 \\
\hline Superficies pintadas & 0 & 1 & 4 & 0 & 0 & 0 & 0 & 0 & 0 & 0 & 0 & 0 & 1 & 0 & 6 \\
\hline indeterminados & 0 & 0 & 1 & 10 & 0 & 3 & 1 & 2 & 0 & 2 & 0 & 0 & 0 & 0 & 19 \\
\hline Indetdeterminados & 0 & 0 & 1 & 10 & 0 & 3 & 1 & 2 & 0 & 2 & 0 & 0 & 0 & 0 & 19 \\
\hline Total por conjunto & 1 & 1 & & 55 & & & 40 & & 8 & 28 & & 9 & & 12 & 154 \\
\hline Total por sector & 1 & & & 56 & & & & & & 97 & & & & & \\
\hline
\end{tabular}

excepción de los indeterminados, no superan el $10 \%$ de la muestra y, entre éstos, sólo tres superan el $5 \%$ (Fig. 4). El sitio se caracteriza, de este modo, por una alta diversidad de formas.
Distribución de los motivos en la cueva

Los motivos se distribuyen en tres sectores de la cueva; en el primero sólo se registró una 

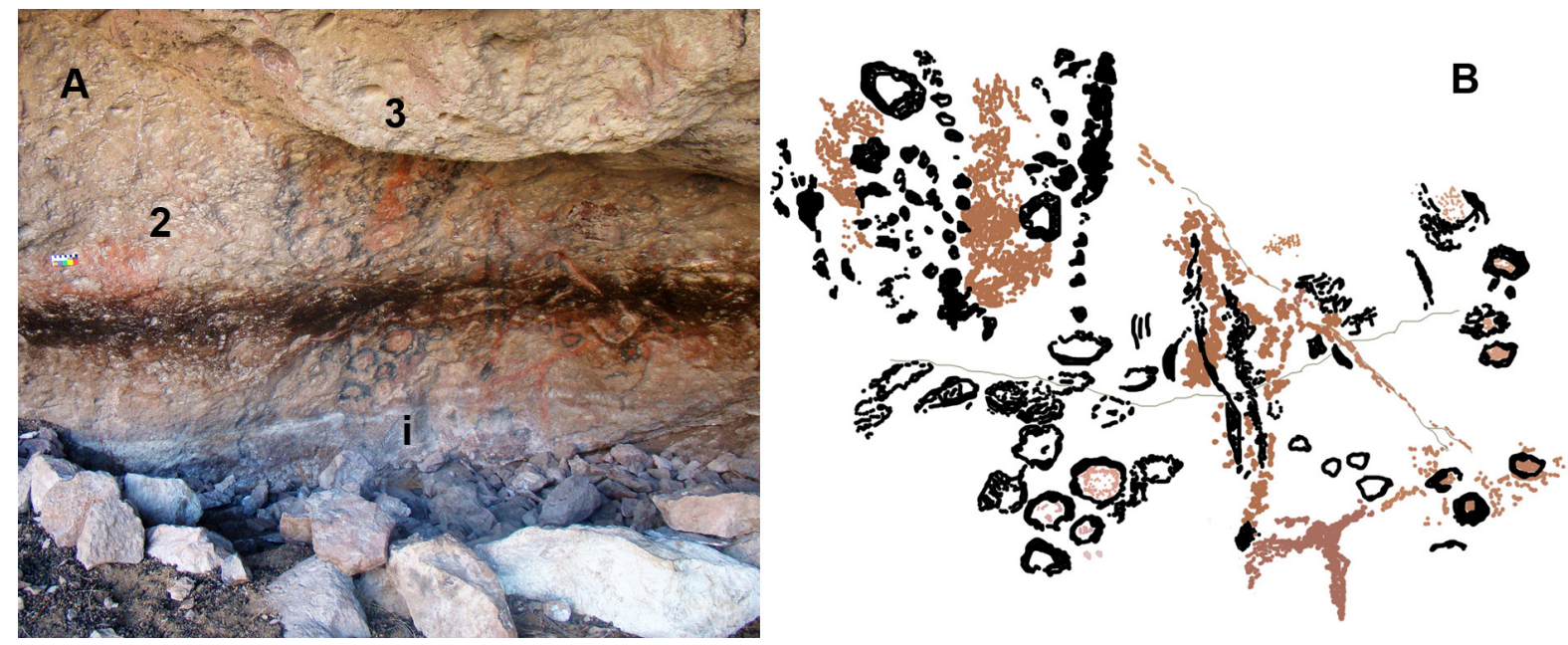

Fig. 3. A) Detalle del sector II donde se observa la proximidad entre el arte rupestre y los entierros humanos. 2 y 3 : conjuntos con arte rupestre; i: contexto mortuorio 1. B) Calco a partir de foto del conjunto 3.

pisada de Rheido $(0,6 \%)$ en color blanco de $33 \mathrm{~cm}$ de largo por $18 \mathrm{~cm}$ de ancho ( $\mathrm{n}^{\circ} 1$ en Fig. 2). En el sector 2 se observa una superficie pintada de rojo que abarca $40 \mathrm{~cm}$ de alto por $90 \mathrm{~cm}$ de ancho ( $n^{\circ} 2$ en Fig. 2), y un conjunto conformado por motivos rojos y negros ( $\mathrm{n}^{\circ} 3$ en Fig. 2). Debajo de estas pinturas se localizaba el contexto mortuorio 1 (i en Fig. 2 y Fig. 3 a). El sector 2 presenta una alta densidad de motivos ( $n=56,36,4 \%)$, en su mayor parte circulares, seguidos por líneas de puntos y de trazo continuo (Tabla 2). Estas pinturas son generalmente de color negro, aunque también hay casos de bicromía representados por circunferencias negras con pintura roja en su interior; las pinturas rojas subyacen a las negras (Fig. 3 a y b).

El sector 3 es el de mayor extensión y el que exhibe la mayor cantidad y variabilidad de motivos y colores ( $n=97,63 \%$; Tabla 2). En éste se delimitaron cinco conjuntos ( $n^{\circ} 4$ a 8 en Fig. 2);

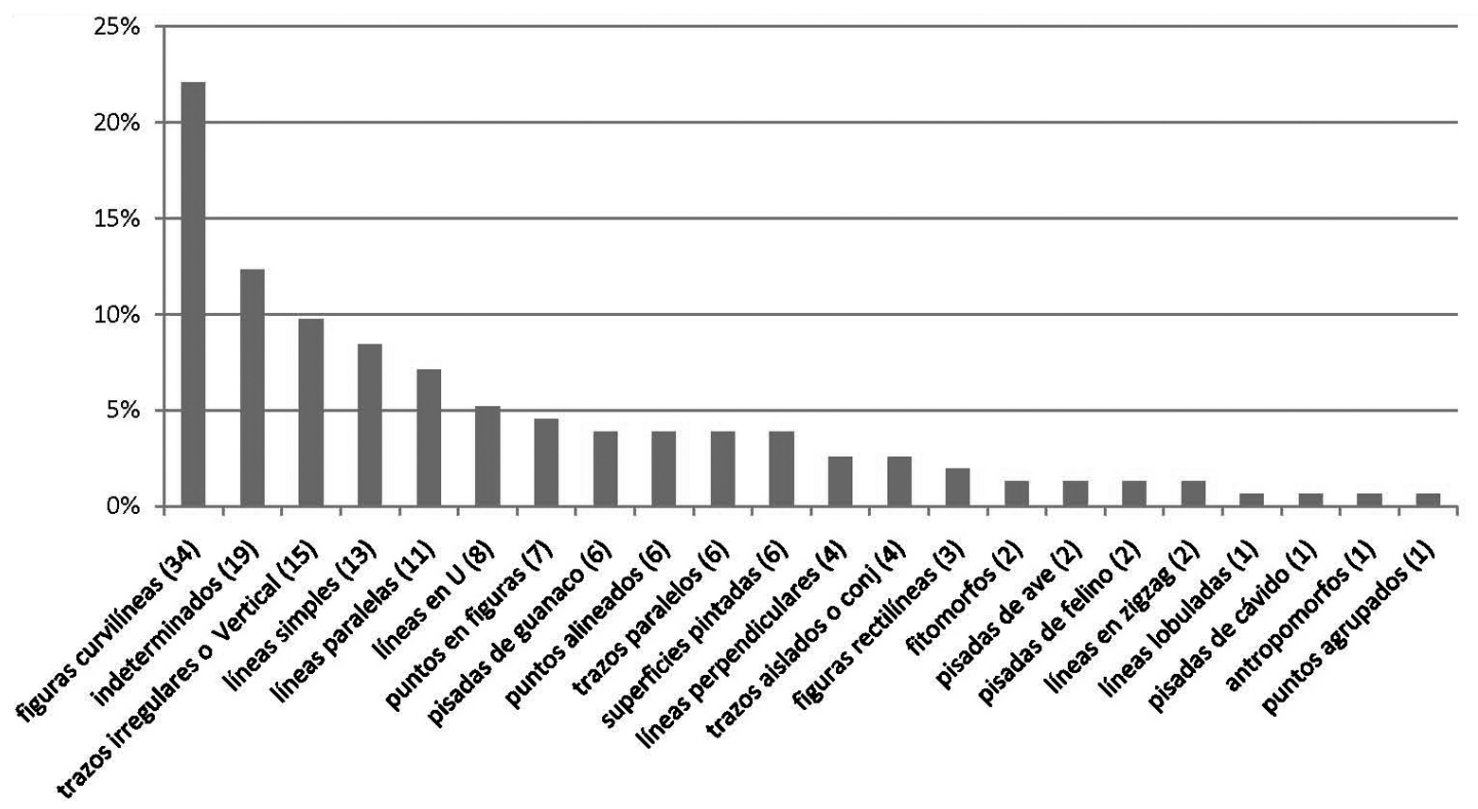

Fig. 4. Porcentajes de subtipos de motivos en Cueva Galpón. Los números entre paréntesis indican las frecuencias de motivos. 
los dos primeros están ubicados a mayor altura que los restantes (desde ca. 1,6 m de distancia al suelo actual). La forma combada del sustrato rocoso donde se ubica parte del conjunto 4 y el tamaño grande de las pinturas (con motivos que alcanzan los $70 \mathrm{~cm}$ de longitud) condicionan su observación, que resulta más fácil al tomar distancia (i.e., desde la boca de la cueva). Cerca de los motivos la visualización más óptima se logra horizontalmente.

Como se mencionó, los conjuntos del sector 3 son muy variables entre sí tanto en lo que respecta a las formas como a los colores utilizados: blanco, rojo y rojo-negro en el conjunto 4 , rojo en el conjunto 5, negro y rojo en los conjuntos 6 y 7 , y blanco en el conjunto 8. En el conjunto 4 se registraron todos los subtipos definidos entre las líneas, abarcando desde formas simples hasta aquellas de alta complejidad como un motivo compuesto en "U" invertida (Fig. 5 a). Entre los biomorfos se incluye un posible "antropomorfo" de tratamiento lineal, dos figuras "fitomorfas" -que se asemejan a una rama y a una hoja esquematizada, respectivamente-, y una pisada que podría corresponder, de acuerdo con los criterios planteados en Carden (2008), a un ave vadeadora debido al ángulo interdigital y a la presencia del dedo trasero (Fig. 5 a). En el conjunto 5 se destaca por su tamaño ( $40 \mathrm{~cm}$ de alto por 50 de ancho) y complejidad una trama de circunferencias adosadas de la cual se desprenden líneas paralelas. Asociado a este motivo y a dos series de trazos paralelos ("peiniforme") se registró un motivo compuesto
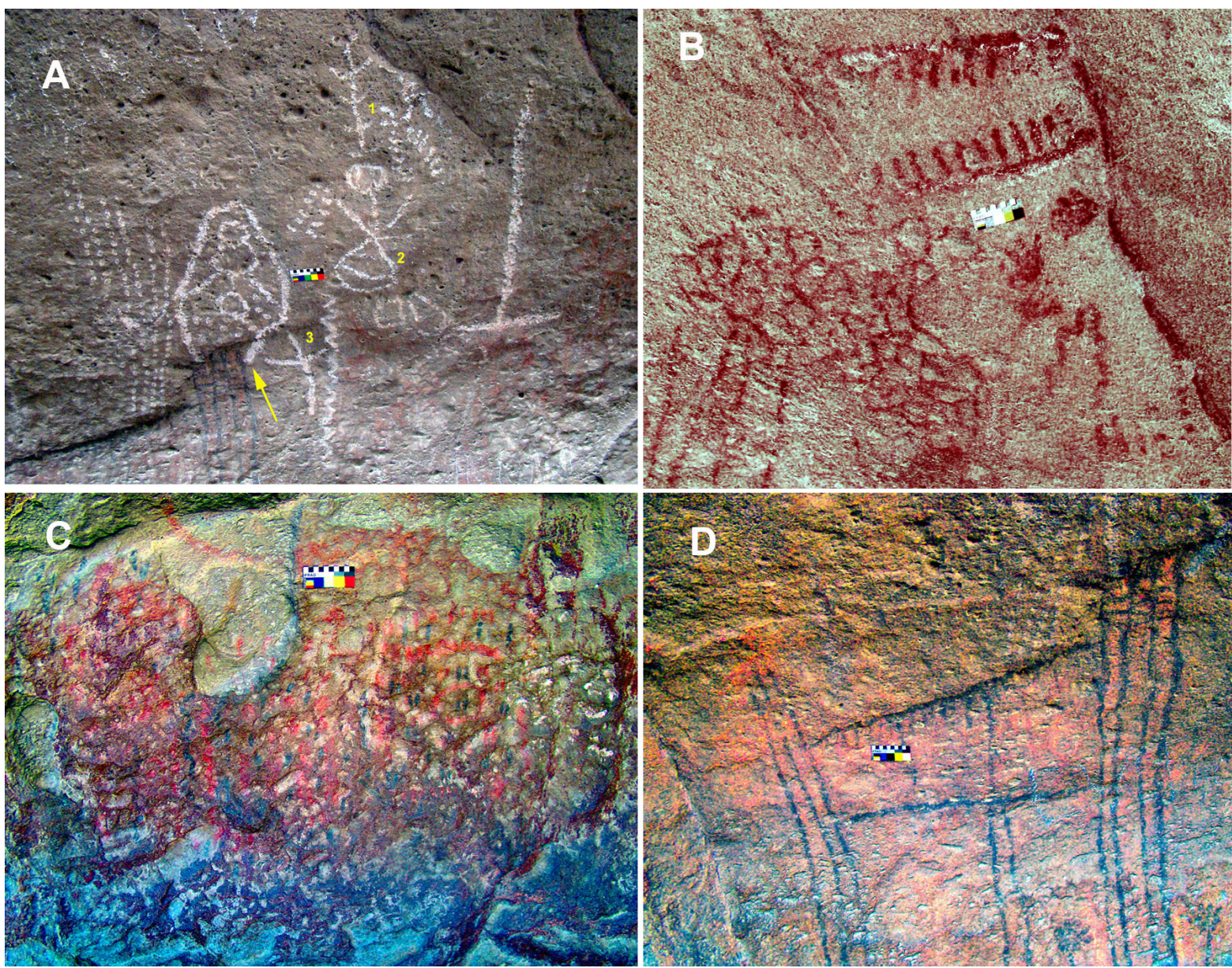

Fig. 5. Variabilidad de los conjuntos del sector 3. A) Detalle del conjunto 4 donde se observan figuras biomorfas y formas geométricas de variada complejidad. 1: "fitomorfos", 2: "antropomorfo", 3: "zoomorfo" (pisada de ave). La flecha señala la superposición "blanco sobre negro sobre rojo". B) Conjunto 5. Debajo de la escala se observa motivo que se asemeja a una pisada de mara. C) Conjunto 6. D) Conjunto 7. Las imágenes fueron tratadas con D Stretch. 
de tamaño pequeño muy desvaído cuyo diseño se asemeja a las pisadas de los cávidos, especialmente los rastros delanteros de la mara -Dolichotis patagonum (T. Manera comunicación personal; Rumboll et al. 2011, p. 33; Fig. 5 b, Fig. 6). De ser correcta la interpretación, el motivo es bastante singular en la región donde hasta el momento sólo se han identificado huellas de roedores grabadas en el sitio Casa de Piedra de Ortega, SO de Río Negro (Fernández, 2009).

Si bien los conjuntos 6 y 7 comparten los mismos colores (negro y rojo), las composiciones son diferentes: el primero fue básicamente realizado mediante la combinación de trazos cortos, puntos y pisadas de guanaco en forma de rastrilladas (Fig. 5 c), mientras que el segundo está compuesto por líneas paralelas de casi $1 \mathrm{~m}$ de longitud interconectadas por transversales y asociadas a pisadas de felino (Fig. $5 \mathrm{~d}$ ). La mayor parte de los motivos del conjunto 8 consisten en líneas diversas (simples, paralelas, perpendiculares y en "U"). Entre éstas se destaca un motivo en "U" con líneas transversales internas de $40 \mathrm{~cm}$ de largo.

Diversidad de motivos y tamaños por color

La distribución de colores en Cueva Galpón es bastante homogénea, con predominio del negro ( $n=54,35 \%)$, seguido por el rojo $(n=47,30 \%)$ y el blanco ( $\mathrm{n}=38,25 \%)$; la combinación de rojo y negro fue registrada en 15 casos (10\%). En cuanto a la relación entre clase de motivo y color, se observa que las superficies pintadas sólo se
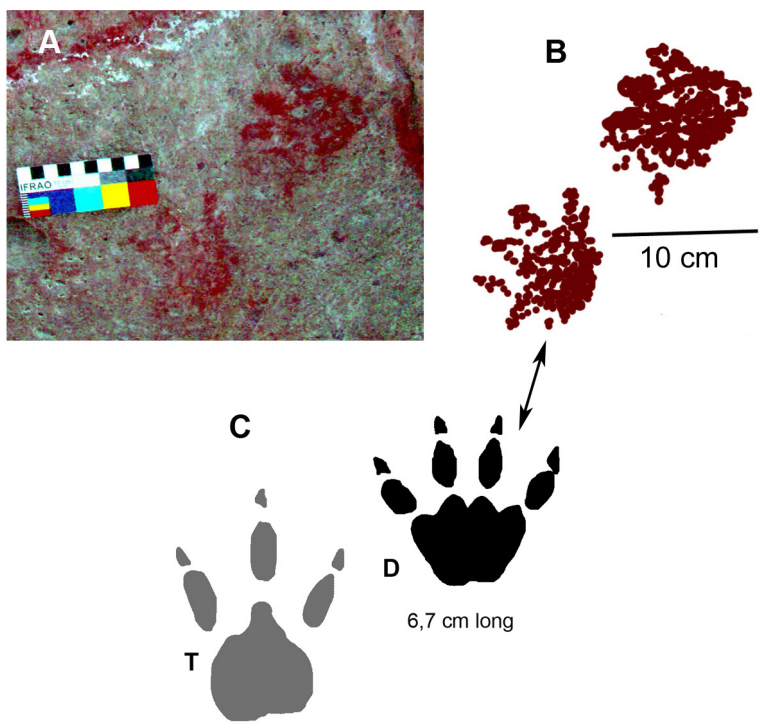

Fig. 6. Detalle de motivo interpretado como pisada de mara. A. Imagen tratada con D Stretch. B. Calco a partir de foto. C. Pisada de mara tomada de Rumboll et al. 2011: 33. D: pisada delantera, T: pisada trasera.

realizaron en rojo, mientras que en el resto de las clases (biomorfos, puntos, trazos, líneas y figuras geométricas) se observan los tres colores. Las líneas son los motivos más abundantes del color blanco, las figuras circulares son los únicos motivos en la bicromía del negro con rojo, mientras que el negro y el rojo exhiben cantidades más homogéneas de motivos (Tabla 2).

Si se consideran las categorías de motivos con mayor detalle, se observa que algunos fueron realizados en distintos colores y otros sólo en uno.
Fig. 7. Esquema de los motivos compartidos entre los distintos colores de Cueva Galpón. R: rojo, N: negro, $\mathrm{N}$ y $\mathrm{R}$ : negro y rojo, B: blanco.

\begin{tabular}{|c|c|c|c|c|c|c|c|c|c|c|c|c|}
\hline $\begin{array}{l}\text { Motivos } \\
\text { Comunes }\end{array}$ & $\begin{array}{l}10 \\
11 \\
N\end{array}$ & & $\begin{array}{l}00 \\
00 \\
00 \\
00\end{array}$ & |ll| & 1 & & & $\pi$ & & & & \\
\hline $\mathbf{R}$ & $X$ & $X$ & $X$ & $X$ & $x$ & & $x$ & $X$ & $x$ & $x$ & $X$ & \\
\hline $\mathbf{N}$ & $x$ & $X$ & $X$ & $X$ & $x$ & $X$ & $x$ & & & $X$ & $X$ & $X$ \\
\hline N y R & & & & & & & & & & & & $x$ \\
\hline B & & & $X$ & & $x$ & $X$ & $X$ & $X$ & $x$ & $x$ & $x$ & \\
\hline
\end{tabular}




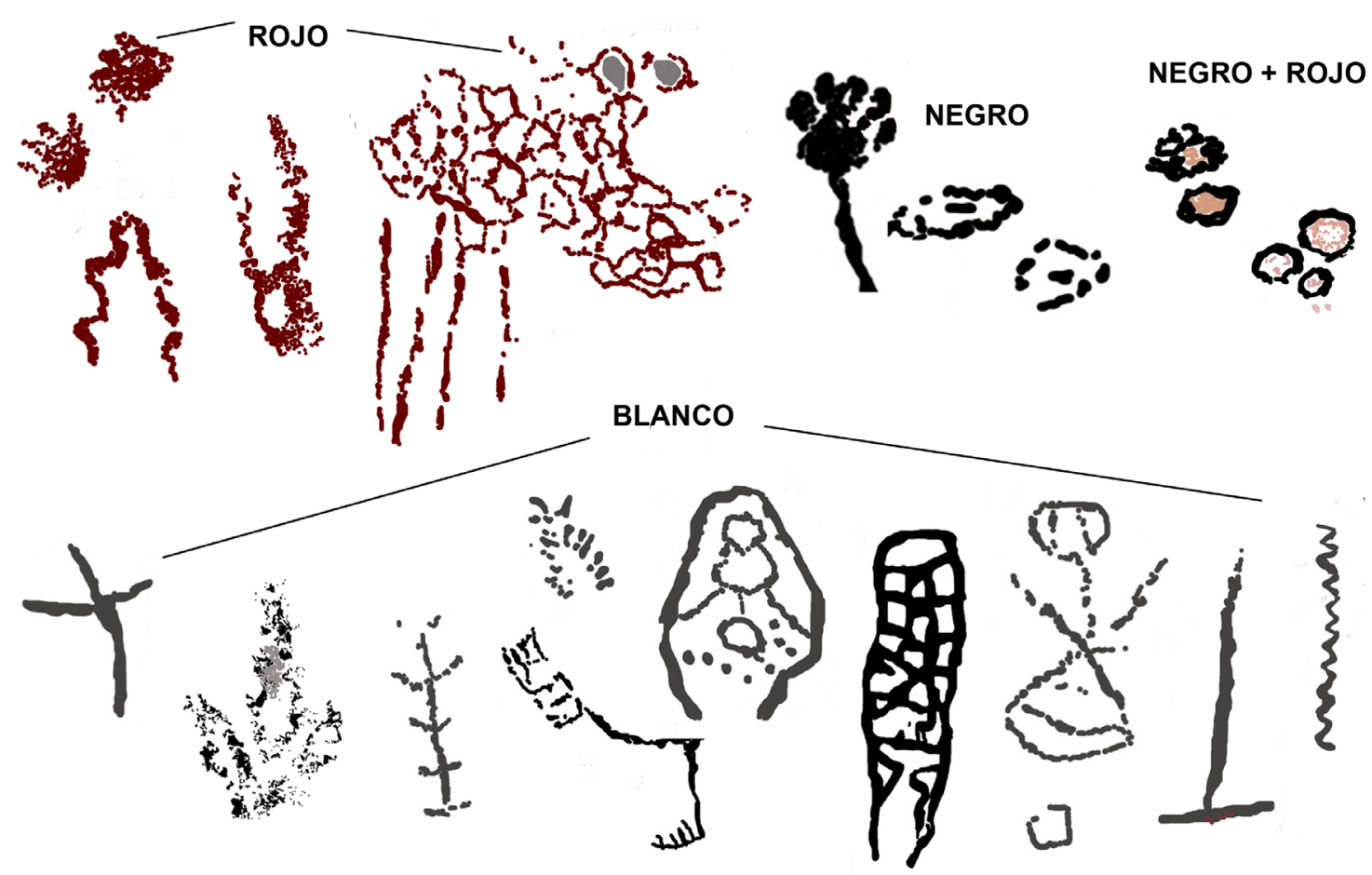

Fig. 8. Motivos exclusivos por color.

Los motivos compartidos son formas simples generalmente representadas por los tres colores. Las repeticiones más frecuentes se observan entre rojo y negro, rojo y blanco, y negro y blanco (Fig. 7). Con excepción de las pisadas de guanaco que se repiten en rojo y negro, cada color se diferencia por el tipo de rastros que representa: pisadas de cávidos en rojo, pisadas de felino en negro y pisadas de ave en blanco. Este último es el color que presenta la mayor cantidad de formas exclusivas, incluyendo una amplia variedad de líneas complejas (Fig. 8).

En líneas generales los motivos de color blanco son los que presentan el mayor tamaño promedio (27 cm de alto por 14 de ancho) $)^{3}$; les siguen los rojos $(22 \times 10 \mathrm{~cm})$, los negros (15 x $9 \mathrm{~cm}$ ) y los combinados en negro y rojo (5 x 8 $\mathrm{cm})$. Si se consideran diferentes rangos de tamaños con respecto al alto, se observa que sólo el blanco y el rojo incluyen motivos que superan el metro; en ambos casos de líneas superpuestas a grietas. El rango de 50 a $99 \mathrm{~cm}$ de alto, aunque poco frecuente, está cubierto por los tres colores. El rojo y el blanco predominan en el rango de 20 a $49 \mathrm{~cm}$, mientras que el negro y el negro combinado con rojo presentan generalmente un alto menor a 10 $\mathrm{cm}$ (Fig. 9). A pesar de las tendencias detectadas, no se puede establecer una separación neta entre los colores a partir de sus dimensiones debido a que, excepto los motivos en bicromía, el resto se manifiesta en todos los tamaños.

Análisis de las superposiciones

La mayor parte de las superposiciones registradas (25/29) corresponden a motivos negros sobre rojos; estos últimos generalmente son superficies pintadas. Las cuatro superposiciones restantes son muy variables y no muestran un patrón definido: el blanco predomina en posición superior sobre el rojo y el negro pero también aparece debajo del rojo. Asimismo, se registró un caso de rojo sobre negro (Tabla 3).

Elanálisis sugiere que el rojo fue el primercolor utilizado en la secuencia de ejecución de los motivos de Cueva Galpón. En los casos de superposición de negro sobre rojo, no resulta sencillo distinguir si el rojo subyacente corresponde al mismo evento de producción que el negro o a eventos previos. 
La existencia de una superposición de rojo sobre negro abre la posibilidad de una producción relativamente sincrónica, sustentada además por la presencia de motivos en bicromía (circulares del conjunto 3) y de conjuntos conformados por motivos con fuertes semejanzas morfológicas y técnicas donde intervienen ambos colores (e.g., conjunto 6). Aunque la distancia temporal entre la producción del rojo y el negro no es fácil de definir en todos los casos, ambas situaciones (diacrónica o sincrónica) implican planes compositivos donde interactuaron ambos colores.

La superposición del blanco sobre el rojo y el negro (sector 3 ) sugiere que el blanco corresponde a un evento posterior de pintado. Esta idea se refuerza a partir de: 1) las diferencias detectadas en su composición interna con respecto a los otros

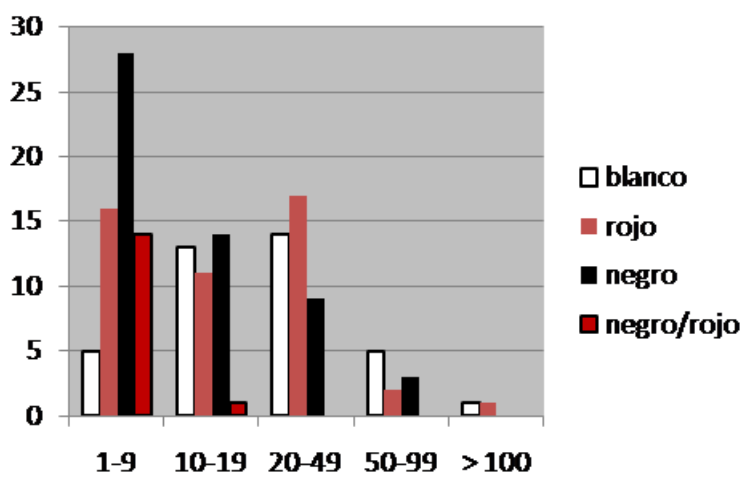

Fig. 9. Distribución de colores según distintos rangos de tamaños (en $\mathrm{cm}$ ).

dos colores -integrada principalmente por una alta variedad de líneas- (Tabla 2 y Fig. 8), 2) su mayor tamaño promedio, 3) su mejor estado de

Tabla 3. Superposiciones detectadas en Cueva Galpón. N/R: negro sobre rojo, R/N: rojo sobre negro, B/N/R: blanco sobre negro sobre rojo, R/B: rojo sobre blanco, B/R: blanco sobre rojo. *: Superposiciones que involucran motivos de diferentes conjuntos.

\begin{tabular}{|c|c|c|c|c|c|c|}
\hline Superposiciones & Motivos arriba & $\begin{array}{l}\text { Motivos } \\
\text { intermedios }\end{array}$ & Motivos abajo & Conjunto & $\mathrm{n}$ & $\%$ \\
\hline \multirow{11}{*}{$\mathrm{N} / \mathrm{R}$} & indeterminado & & superficie pintada & 3 & 3 & \multirow{11}{*}{86} \\
\hline & puntos alineados & & superficie pintada & 3 & 1 & \\
\hline & puntos en circunferencia & & superficie pintada & 3 & 1 & \\
\hline & línea simple & & superficie pintada & 3,7 & 2 & \\
\hline & trazos alineados & & superficie pintada & 7 & 1 & \\
\hline & líneas paralelas & & superficie pintada & 3,7 & 3 & \\
\hline & circunferencia & & superficie pintada & 3 & 6 & \\
\hline & pisada de felino & & superficie pintada & 7 & 2 & \\
\hline & indeterminado & & indeterminado & 3 & 2 & \\
\hline & línea de trazos irregulares & & línea de trazos irregulares & 6 & 2 & \\
\hline & rastrillada de guanaco & & línea de trazos irregulares & 6 & 2 & \\
\hline $\mathrm{R} / \mathrm{N}$ & indeterminado & & indeterminado & 4 & 1 & 3,5 \\
\hline $\mathrm{B} / \mathrm{N} / \mathrm{R}$ & U invertida compleja & $\begin{array}{l}\text { líneas } \\
\text { paralelas }\end{array}$ & superficie pintada & 4 y $7^{*}$ & 1 & 3,5 \\
\hline $\mathrm{R} / \mathrm{B}$ & indeterminado & & T invertida & 4 y $5^{*}$ & 1 & 3,5 \\
\hline $\mathrm{B} / \mathrm{R}$ & línea simple & & trama de circunferencias & 5 y $8^{*}$ & 1 & 3,5 \\
\hline TOTAL & & & & & 29 & $100 \%$ \\
\hline
\end{tabular}


preservación y 4) su localización particular, que sugiere la selección de un espacio distintivo a partir del uso de un plano diferente y una altura superior a la del resto de los motivos. Sin embargo, algunos casos también señalan la sincronía entre el blanco y el rojo, como por ejemplo los motivos blancos que se encuentran sobre y debajo de pinturas rojas en el sector 3 (Tabla 3).

Los resultados sugieren, por lo tanto, que primero se habrían realizado los conjuntos rojos $y$ negros $(2,3,6$ y 7$)$ y que luego se incorporaron los conjuntos rojos y blancos (1, 4, 5 y 8). La secuencia propuesta implica diferentes episodios de producción de pinturas rojas.

\section{DISCUSIÓN}

El primer aspecto a considerar para la interpretación de las pinturas rupestres de Cueva Galpón es que el sitio no presenta evidencias de haber sido utilizado como área residencial, aún cuando no hay disponible en este sector de las sierras de Pailemán abrigos tan grandes ni tan reparados. Como se ha señalado, durante las excavaciones y los sondeos estratigráficos no se recuperaron prácticamente correlatos de actividades asociadas a este tipo de contexto (i.e., artefactos líticos, restos de fauna, fogones, alfarería, etc. $)^{4}$. La mayor parte de las evidencias arqueológicas registradas además de las pinturas son restos humanos atribuibles a un mínimo de dos eventos de entierro. Si se tiene en cuenta que los entierros se encuentran en el sector más profundo del abrigo, justo debajo de uno de los conjuntos de pinturas, es razonable plantear algún tipo de asociación entre ambas prácticas.

Como fue señalado, el conjunto 3 de pinturas, cuyos motivos predominantes son figuras circulares negras, en ocasiones combinadas con rojo, se encuentra espacialmente asociado a los entierros, justo por encima del contexto mortuorio 1. La falta de colágeno en las muestras óseas de este último no permitió obtener edades absolutas, aunque la presencia de restos textiles y cobre asociados a ellas como parte del acompañamiento funerario podría sugerir una edad máxima relativamente tardía (tiempos prehispánicos tardíos o posthispáncos tempranos). Sin embargo, esta estimación debe

4 Los pocos materiales de este tipo fueron recuperados en el área de excavación de los entierros y, por lo tanto, no considerarse con cautela porque la validez del uso de la textilería y metales como indicadores de cronología relativa no ha sido testeada para el área de estudio; en nuestro caso nos apoyamos exclusivamente en la antigüedad de algunos de los registros similares más cercanos al sitio (e.g., Berón \& González, 2005; Gómez-Otero, 2003; Pérez de Micou, 2009). Es interesante también el hallazgo del pan de pigmento rojo de grandes dimensiones en el contexto mortuorio 1, cuyo color frotado sobre papel (red 10R 5/8 en la escala Munsell) coincide con el de las pinturas rojas del sector 2 (conjuntos 2 y 3). Esto podría constituir otro correlato de la asociación contextual entre el evento mortuorio y la ejecución de las pinturas, aunque es necesario realizar análisis composicionales de los pigmentos en capa y en pared para validar la hipótesis. Es posible que los restos humanos correspondientes al contexto mortuorio 1 hayan sido enterrados en el lugar con posterioridad a la producción de las pinturas, aunque no puede descartarse una cronología más temprana que la estimada para ellos a partir de la evidencia regional (ca. 500 años AP). En relación con este punto, es oportuno señalar que otros entierros humanos de Norpatagonia con rasgos similares a los del contexto mortuorio 1 de Cueva Galpón (e.g., con evidencias de combustión, textiles y/o cobre) y asignados a momentos de contacto hispano-indígena, han sido asociados a motivos rupestres asignables al "estilo de grecas" (Boschín, 2009; Crivelli et al. 1991), que difieren formalmente de los considerados aquí.

El segundo contexto mortuorio, datado en ca. 3.000 años AP y ubicado a continuación del primero, también se encuentra muy próximo al conjunto 3 de pinturas y es hasta el momento el dato cronológico más confiable para el sitio. Esta estrecha relación espacial es interesante porque si los restos humanos hubiesen sido depositados intencionalmente en proximidad de las pinturas, habría que asumir necesariamente un piso cronológico para el arte cercano a los 3.000 años. Esta edad es coherente con la cronología asignada a motivos similares a los de Cueva Galpón (aunque principalmente realizados mediante la técnica del grabado) localizados en sitios de Patagonia noroccidental y la Meseta

se asume que constituyan el producto de ocupaciones residenciales. 
de Somuncura. Dichos motivos se vinculan formalmente con el "estilo de pisadas", definido sobre todo a partir de la presencia de huellas (de aves, artiodáctilos, felinos y humanos) y diversas clases de puntos, líneas y figuras principalmente curvilineas (Llamazares, 1989; Menghin, 1957). La antigüedad de estos grabados en la cuenca del río Limay fue estimada sobre la base de la edad de los contextos arqueológicos cuyos sedimentos se depositaron por encima de los motivos rupestres. Concretamente, se planteó una edad mínima de $2.710 \pm 100$ años AP para los grabados de las paredes de Casa de Piedra de Ortega (SO de Río Negro), la cual sugería que el comienzo de la producción de motivos pudo ser contemporáneo a las primeras ocupaciones del sitio, datadas en $2.840 \pm 80$ años AP (Crivelli, 1988) (Tabla 4). Una cronología mínima similar se planteó para el inicio de la producción de los grabados (tridígitos y motivos lineales) parcialmente cubiertos por un estrato datado en $2.740 \pm 50$ años AP en la cueva Epullán Grande, Neuquén (Crivelli et al. 1996), y para los de la Cueva Visconti, SO de Río Negro, sellados por un nivel cultural fechado en $2.526 \pm$ 93 años AP (Ceballos \& Peronja, 1983). A partir de argumentos similares se propuso que las edades de los grabados de Cueva Epullán Chica y Alero Carriqueo serían anteriores a $2.200 \pm 60$ y 2.620 \pm 110 años AP, respectivamente (Crivelli, 2006; Crivelli et al. 1996). En este contexto, resulta llamativo que los motivos de Cueva Galpón hayan circulado principalmente en forma grabada en el espacio regional. Aunque la presencia de grabados sobrepintados (Boschín, 2009; Llamazares, 1989) sugiere que esta distribución podría deberse a un problema de preservación, las pinturas de Cueva Galpón señalan que la información transmitida a través de los colores fue relevante en el sitio.

Aunque la proximidad entre las pinturas rupestres y los entierros es elocuente, hasta el momento no hay datos en Cueva Galpón que permitan plantear con precisión el orden temporal en que se llevaron a cabo ambos tipos de prácticas. Esto se debe, en parte, a que las pinturas estaban cubiertas por una capa de guano pero no por el paquete sedimentario que contenía los entierros. Por lo tanto, no es posible plantear una cronología relativa para el arte sobre la base de sellos arqueológicos. A partir de la información disponible (fechados del contexto mortuorio 2 y proximidad entre los entierros y el conjunto 3) se propone que las prácticas inhumatorias y de producción de arte estuvieron vinculadas y habrían tenido lugar en un momento cercano a los 3.000 años AP. El vínculo entre los entierros y el arte rupestre se basa en un argumento más espacial que temporal, problema sobre el que se podrá avanzar estableciendo si el pigmento en capa está asociado a la producción de arte rupestre, resolviendo mejor la cronología de ambos contextos mortuorios e intentando datar radiocarbónicamente a las pinturas.

\section{CONSIDERACIONES FINALES}

En este trabajo se han descripto y analizado los rasgos principales de las manifestaciones rupestres de Cueva Galpón y propuesto algunas ideas generales sobre su asociación contextual y anclaje cronológico. Sobre la base de la presencia en capa de pigmento rojo en el contexto mortuorio 1 , de su similitud cromática con las pinturas rupestres del sector 2 , y teniendo en cuenta la ajustada asociación espacial entre ambos, se planteó la hipótesis de su vinculación. Además, se propuso una posible pene-contemporaneidad entre el segundo contexto mortuorio (datado en ca. 3.000 años AP) y el mismo sector de pinturas, la cual que se sustenta en las semejanzas formales con motivos de la región con una cronología similar. Si se vincula esta propuesta con la secuencia de producción de arte rupestre definida para la cueva sobre la base de las superposiciones, es posible plantear que alrededor de 3.000 años AP se produjeron las inhumaciones (al menos las del contexto mortuorio 2); en un momento cercano a esta fecha se realizaron las pinturas rojas y negras del sector $2 y$, probablemente, los demás conjuntos rojos y negros (6 y 7 del sector 3 ). Con posterioridad se realizaron las pinturas blancas y rojas en otros espacios de la cueva (motivo 1: sector 1 , conjuntos 4, 5 y 8: sector 3). En esta secuencia aún resta establecer la cronología del contexto mortuorio 1 y su vinculación con el arte rupestre.

La evidencia proveniente de los entierros humanos y de las pinturas rupestres permite plantear el uso recurrente de un espacio aparentemente desconectado de la esfera cotidiana o doméstica. Las fechas obtenidas a partir de 
uno de los contextos mortuorios (ca. 3.300 años AP) y la cronología relativa más tardía de varios objetos arqueológicos asociados al otro (restos de cobre y de textiles) sugiere el re-uso del mismo lugar para prácticas de entierro. En cuanto al arte rupestre, la secuencia de su producción muestra variabilidad en el interior de cada evento (e.g., en las pinturas rojas y negras predominan los círculos en el conjunto 3, los trazos, puntos y pisadas de guanaco en el conjunto 6 y las líneas largas asociadas a pisadas de felinos en el conjunto 7). Sin embargo, si se comparan los diferentes eventos no se observan diferencias estilisticas sustanciales. A partir de la incorporación de las pinturas rojas y blancas en el sector 3 no se introducen diseños radicalmente diferentes a los rojos y negros sino que se reproducen motivos previamente realizados en dichos colores (e.g., líneas largas que resaltan grietas, líneas paralelas, pisadas de animales, etc.). Sin embargo, y especialmente a través del blanco, se amplía el repertorio de imágenes a partir de motivos lineales (por lo general de mayor tamaño) que pueden alcanzar formas muy complejas que no se repiten en el espacio regional, y se busca un nuevo espacio compositivo que requiere un campo visual más amplio. De este modo, si bien el contexto general del arte rupestre apunta hacia prácticas rituales prescriptivas, las pinturas blancas son las más sensibles como indicadoras de los aspectos performativos (Bradley, 1991).

La continuidad en las prácticas de producción de arte rupestre también ha sido propuesta para otros sitios de la región norpatagónica sobre la base de criterios estilísticos, la meteorización diferencial, las exfoliaciones de los soportes, las diferencias técnicas y el análisis de las pátinas (Blanco et al. 2015; Boschín, 2009; Ceballos \& Peronja, 1983; Crivelli, 1988, 2006; Crivelli et al. 1996). Este patrón está inmerso en el contexto de un aumento demográfico durante el Holoceno tardío (ca. 3.000 años AP), momento para el cual se registra una mayor cantidad de sitios arqueológicos que

5 Aunque en términos generales la información proveniente de cuevas y aleros no señala asociaciones entre el arte rupestre y los contextos mortuorios, existen antecedentes que apuntan a este tipo de relaciones en sitios a cielo abierto. Una de estas propuestas interpretativas se refiere a la relación de los grabados asignados a los estilos de "pisadas" y de "grecas" del evidencian ocupaciones más continuas a lo largo del tiempo, probablemente vinculadas a un proceso de territorialidad creciente (Barberena et al. 2015; Boschín, 2009; Crivelli Montero, 2010).

En este contexto, la ausencia de evidencias residenciales en Cueva Galpón es bastante llamativa si se compara con la información arqueológica regional proveniente de sitios en abrigos con arte rupestre y entierros humanos localizados en ambientes boscosos y de estepa en Patagonia septentrional (provincias de Río Negro y Neuquén). Estos sitios muestran una historia ocupacional compleja de los espacios reparados que sugiere su uso diacrónico para diferentes propósitos. En algunos casos las evidencias sugieren la contemporaneidad del arte rupestre con las ocupaciones residenciales pero no con los entierros humanos; los grabados de Casa de Piedra de Ortega son anteriores al evento inhumatorio que se ubica inmediatamente debajo de una pared con motivos en zig-zag, mientras que las pinturas de "grecas" de Población Anticura y Puerto Tranquilo I son posteriores a los entierros humanos (Albornoz \& Cúneo, 2000; Fernández, 2001, 2009; Fernández et al. 2012). En otros sitios, como Epullán Grande y Cueva 1 del río Pichileufú, el arte rupestre no es contemporáneo a las ocupaciones residenciales ni a los entierros (Boschín, 2009; Crivelli et al. 1996). Aunque no se descarta que la presencia previa de arte rupestre haya incidido simbólicamente en la selección de espacios funerarios (o viceversa), no se han establecido vinculaciones directas entre ambas actividades $^{5}$ (Tabla 4).

En el marco de la información relevada, Cueva Galpón presenta, como el resto de los sitios de la región, evidencias que apuntan a usos recurrentes de un mismo espacio. Sin embargo, difiere de estos últimos en la ausencia de indicadores de uso residencial. La probable relación entre las pinturas y las prácticas inhumatorias constituye, por lo tanto, un rasgo infrecuente para el área norpatagónica en el período considerado y sugiere

Cerro Yanquenao (Chubut) con un enterratorio cercano (Gradin, 1989), y la segunda plantea que los enterratorios de piedra en forma de "chenque" del cañadón Quetrequile (sitio Cides II) no se pueden desvincular de las pinturas rupestres rectilíneas escalonadas que se ubican en estrecha proximidad a los mismos (Boschín, 2009). 


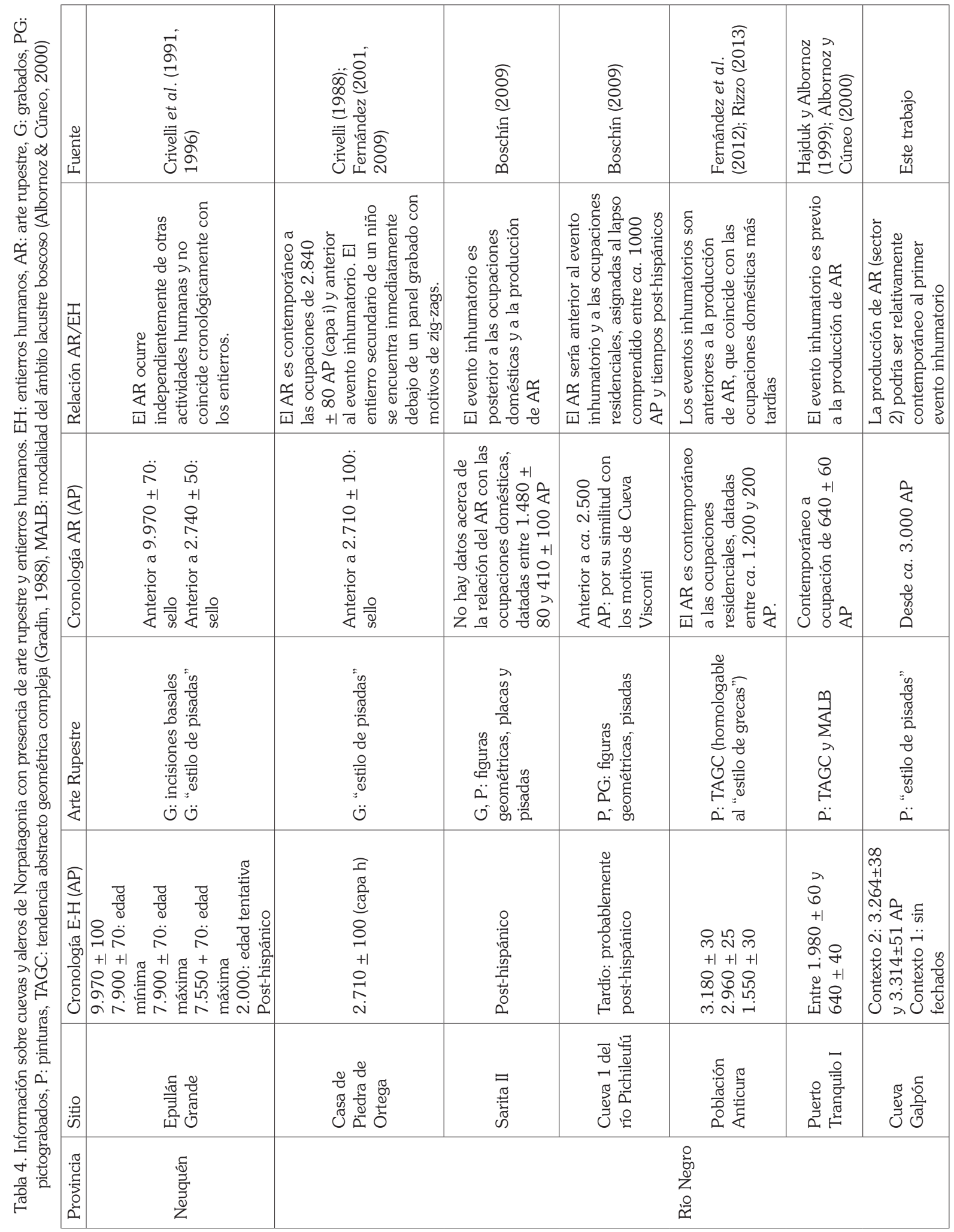


que su ocupación estuvo más ligada a esferas sagradas, cargadas de simbolismo y ritualidad. La resolución cronológica de los entierros y del arte rupestre permitirá entender con mayor profundidad el grado de interdependencia que existió entre ambos tipos de prácticas.

\section{AGRADECIMIENTOS}

Queremos expresar nuestro agradecimiento a María Inés Kopp y Romina Rial por su entusiasmo y asistencia permanente antes, durante y después de los trabajos de campo. A la familia Contreras por su amabilidad y predisposición para que podamos trabajar dentro de su propiedad. A Violeta Di Prado, Emiliano Mange, Alejandro Serna y Agustina Ramos Van Rapp por su colaboración en los trabajos de campo, y a Gustavo Martínez por sus comentarios sobre versiones previas del manuscrito. A Teresa Manera por su orientación en la identificación de motivos de "pisadas". Este trabajo fue realizado con financiamiento de la ANPCyT (PICT 2007-264) y CONICET (PIP $338 / 10$ ) y en convenio con la Secretaría de Cultura de la provincia de Río Negro.

\section{BIBLIOGRAFÍA}

Albornoz, A. M. (1996). Sitios con arte rupestre en los alrededores del Lago Nahuel Huapi (Río Negro). En J. Gómez-Otero (Ed.), Arqueología. Sólo Patagonia (pp. 123-130). Puerto Madryn, Argentina: CENPATCONICET.

Albornoz, A. M. \& Cúneo, E. M. (2000). Análisis comparativo de sitios con pictografías en ambientes lacustres boscosos de Patagonia Septentrional: Lagos Lacar y Nahuel Huapi (Provincias de Río Negro y Neuquén). En M. M. Podestá y M. de Hoyos (Eds.), Arte en las Rocas. Arte rupestre, Menhires y Piedras de Colores en Argentina (pp. 163-174). Buenos Aires, Argentina: Sociedad Argentina de Antropología y Asociación Amigos del Instituto Nacional de Antropología.

Aschero, C. A. (1988). Pinturas rupestres, actividades y recursos naturales: un encuadre arqueológico. En H. Yacobaccio (Ed.), Arqueología Contemporánea Argentina, Actualidad y Perspectivas (pp. 109-145). Buenos Aires, Argentina: Ediciones Búsqueda.

Aschero, C. A. (1996). ¿Adonde van esos guanacos? En J. Gómez-Otero (Ed.), Arqueología. Solo Patagonia (pp. 153-152). Puerto Madryn, Argentina: CENPATCONICET.

Barberena, R., Prates, L. \& De Porras, M. E. (2014). The human occupation of northwestern Patagonia (Argentina): Paleoecological and chronological trends. Quaternary International, 356, 111-126.

Berón, M. \& González, L. (2005). Análisis de composición de adornos metálicos de un contexto funerario de cazadores-recolectores. El sitio Chenque I, provincia de La Pampa. En Actas del Primer Congreso Argentino de Arqueometría, Rosario. En prensa.

Blanco, R. V. (2015). El arte rupestre en los macizos del Deseado y Somuncurá: la producción de grabados y pinturas entre cazadores-recolectores desde el Holoceno medio. (Tesis Doctoral Inédita). Facultad de Ciencias Naturales y Museo, Universidad Nacional de La Plata. La Plata.

Blanco, R. V., Miotti, L. L. y Carden, N. (2015). El arte rupestre del nordeste de la meseta de Somuncurá: caracterización inicial e integración regional. Mundo de Antes, 8(2013), 83-103.

Borella, F., Cardillo, M., Favier Dubois, C. M. \& Alberti, J. (2015). Nuevas investigaciones arqueológicas entre Punta Pórfido y Punta Odriozola: implicancia para el entendimiento de la dinámica de las ocupaciones humanas en la costa oeste del Golfo San Matías (Río Negro). Relaciones de la Sociedad Argentina de Antropología 40. En prensa.

Boschín, M. T. (2009). Tierra de hechiceros. Arte Indígena de Patagonia Septentrional Argentina. Salamanca, España: Ediciones Universidad de Salamanca.

Boschín, M. T. \& Casamiquela, R. (2001). Patagonia. 13.000 años de historia. Buenos Aires, Argentina: Emecé.

Bradley, R. (1991). Ritual, Time and History. World Archaeology, 23(2), 209-219.

Bruch, C. (1904). La piedra pintada de El Manzanito (territorio del Río Negro). Revista del Museo de La Plata XI, 7172.

Busteros, A., Giacosa, R. \& Lema, H. (1998). Hoja Geológica 4166-IV, Sierra Grande. Buenos Aires: Servicio Geológico Minero Argentino, Boletín 241.

Cáceres, I. \& Berenguer, J. (1996). El caserío Santa Bárbara 41 y su relación con la w'aka de Taira. Chungara, 28(1-2), 381-393.

Carden, N. (2008). Imágenes a través del tiempo. Arte rupestre y construcción social del paisaje en la Meseta Central de Santa Cruz. Buenos Aires, Argentina: Sociedad Argentina de Antropología.

Carden, N. (2013). Sobre diseños, lugares y prácticas sociales 
en el Macizo del Deseado. En I. Gordillo y J. M. Vaquer (Eds.). Espacialidad en Arqueología. Métodos y aplicación (pp. 23-74). Quito, Ecuador: Abya - Yala.

Carden, N. \& Borella, F. (2015). Symbols by the sea: the first recording of Atlantic coastal rock art in Patagonia (Punta Odriozola, Río Negro, Argentina). Aceptado para su publicación en Rock Art Research, 32(2). En prensa.

Casamiquela, R. (1960). Sobre la significación mágica del arte rupestre nordpatagónico. Cuadernos del Sur, 1: 3-39.

Casamiquela, R. (1981). El arte rupestre de la Patagonia. Buenos Aires, Argentina: Ediciones Siringa.

Ceballos, R. \& Peronja, A. (1983). Informe preliminar sobre el arte rupestre de la Cueva Visconti, provincia de Río Negro. Relaciones de la Sociedad Argentina de Antropología, 15, 109-119.

Crivelli, E. A. (1988). Tres sitios con arte rupestre de la banda rionegrina de Alicurá. Anales de la Sociedad Científica Argentina, 218, 1-9.

Crivelli, E. A. (2006). Frecuencia de creación de sitios con arte rupestre en la cuenca media y superior del río Limay (noroeste de Patagonia). En D. Fiore y M. M. Podestá (Eds.), Tramas en la Piedra. Productos y Usos del Arte Rupestre (pp. 63-83). Buenos Aires, Argentina: World Archaeological Congress, Sociedad Argentina de Antropología y Asociación Amigos del Instituto Nacional de Antropología.

Crivelli, E. A. (2010). Arqueología de la cuenca del río Limay. En R. F. Masera (Ed.). Los ríos mesetarios norpatagónicos. Aguas generosas del Ande al Atlántico (pp. 261338). Carmen de Patagones, Argentina: Gobierno de Río Negro-Ministerio de Producción.

Crivelli, E. A. \& Fernández, M. (1996). Paleoindian bedrock petroglyphs at Epullán Grande cave. Rock Art Research 13(2), 124-128.

Crivelli, E. A., Fernández, M. \& Pardiñas, U. (1991). Diversidad estilística, cronológica y contextual en sitios con arte rupestre del Área de Piedra del Águila. En M. Podestá, M. I: Hernández Llosas y S. Renard de Coquet (Eds.). El Arte Rupestre en la Arqueología Contemporánea, (pp. 113-122). Buenos Aires, Argentina.

Crivelli, E. A., Pardiñas, U. F. J., Fernández, M. Bogazzi, M., Chauvin, A., Fernández, V.M. \& Lezcano, M.J. (1996). La Cueva Epullán Grande (provincia del Neuquén, Argentina). Informe de avance. Praehistoria, 2, 185265.

Fernández, J. (1979). Petroglifos del Departamento de Minas, Neuquén. Miscelánea de Arte Rupestre de la
República Argentina. Monografía de Arte Rupestre. Arte Americano, 1, 83-119.

Fernández, M. (2001). La Casa de Piedra de Ortega (provincia de Río Negro). La estratigrafía. Relaciones de la Sociedad Argentina de Antropología, 26, 261-284.

Fernández, M. (2009). Arqueología de la cuenca inferior del arroyo Pichileufú: los cambios sociales a través del análisis de la organización espacial, la incorporación de nuevas tecnologías y las expresiones simbólicas. (Tesis Doctoral Inédita). Facultad de Filosofía y Letras, Universidad de Buenos Aires. Buenos Aires.

Fernández, P., Carballido Calatayud, M., Bellelli, C. \& Podestá, M.M. (2012). Tiempo de cazadores. Cronología de las ocupaciones humanas en el valle del río Manso inferior (Río Negro). En A. F. Zangrando, R. Barberena, A. Gil, G, Neme, M. Giardina, L. Luna, C. Otaola, S. Paulides, L. Salgán y A. Tívoli, (Eds.). Tendencias teóricometodológicas y casos de estudio en la arqueología de la Patagonia (pp. 167-175). San Rafael, Argentina: Museo de Historia Natural de San Rafael.

Giacosa, R. E. (1993). El Ciclo Eruptivo Gondwánico en el área de Sierra Pailemán, Macizo Nordpatagónico, Argentina. $12^{\circ}$ Congreso Geológico Argentino y $2^{\circ}$ Congreso Nacional de Hidrocarburos, Actas, 4: 113119, Mendoza.

Gómez-Otero, J. (2003). Movilidad y contactos en la costa centro-norte de Patagonia argentina en tiempos pre y posthispánicos. En R. Mandrini y C. D. Paz (Eds.). Las fronteras hispanocriollas del mundo indigena latinoamericano en los siglos XVIIIXIX. Un estudio comparativo, (pp. 287-312). Neuquén, Argentina: UNCo, UNCPBA, UNS.

Gómez-Otero, J. \& Vallejo, M. (1996). Cañadón Encerrado (Chubut): un sitio con pinturas rupestres muy próximo a la costa en Patagonia. En J. Gómez-Otero (Ed.). Arqueología: sólo Patagonia (pp. 163-171). Puerto Madryn, Argentina: CENPAT-CONICET.

Gradin, C. J. (1978). Algunos aspectos del análisis de las manifestaciones rupestres. Revista del Museo Provincial, I: 120-137.

Gradin, C. J. (1988). Caracterización de las tendencias estilísticas del arte rupestre de la Patagonia (provincias de Río Negro, Chubut y Santa Cruz). Contribución al estudio del arte rupestre sudamericano. Boletín de la SIARB, 2, 54-67.

Gradin, C. J. (1989). Los grabados rupestres del Cerro Yanquenao en la provincia del Chubut. Rawson, Argentina: Publicación del gobierno de la provincia del Chubut. 
Gradin, C. J., Aguerre, A. M. \& Albornoz, A. M. (2003). Arqueología de Río Negro. Viedma, Argentina: Secretaría de Estado de Acción Social de Río Negro.

Hajduk, A. \& Albornoz, A. M. (1999). El sitio Valle Encantado 1, su vinculación con otros sitios: un esbozo de la problemática local diversa del Nahuel Huapi. En R. Goñi (Ed.). Soplando en el viento (pp. 371-392). Neuquén, Argentina: Universidad Nacional del Comahue.

Harrington, T. (1932). Algunas pictografías de la región cordillerana de los territorios de Río Negro y Chubut. Physis, 11, 306-307.

Hernández Llosas, M. I. (1985). Diseño de Investigación para Investigaciones Rupestres. Buenos Aires, Argentina: PROINDARA, FECIC, IAHH.

León, R. J. C., Bran, D., Collantes, M., Paruelo, J. M. \& Soriano, A. (1998). Grandes unidades de vegetación de la Patagonia Extra-andina. Ecología Austral, 8, 125144.

Llamazares, A. M. (1989). El estilo "Pisadas" en la Patagonia argentina. Análisis de su formulación y algunos datos sobre una posible modalidad septentrional. Boletín de la SIARB, 3, 48-56.

Maisonneuve, J. (2005). Las Conductas Rituales. Buenos Aires, Argentina: Nueva Visión.

Martel, A., Rodríguez Curletto, S. \& Del Bel, E. (2012). Arte Rupestre y Espacios de Memoria: las representaciones del sitio Confluencia (Antofagasta de la Sierra, Catamarca, Argentina). Revista Chilena de Antropología, 25(1), 121-162.

Menghin, O. (1957). Estilos del Arte Rupestre de Patagonia. Acta Praehistórica, I, 57-87.

Paruelo, J., Beltrán, A., Jobbágy, E., Sala, O. \& Golluscio, R. (1998). The Climate of Patagonia: general patterns and controls on biotic processes. Ecología Austral, 8: 85101.

Pastor, S. (2012). Arte rupestre, paisaje y tensión social. Un caso de estudio en Córdoba (Argentina). Revista Chilena de Antropología, 26(2), 7-32.

Pedersen, A. (1978). Las pinturas rupestres del Parque Nacional Nahuel Huapi y sus posibles proyecciones prehistóricas. Anales de Parques Nacionales, XIV, 7-43.

Pérez de Micou, C. (2009). El sitio Alero Mazquiarán, Chubut. En C. Pérez de Micou, M. Trivi de Mandri y L.S Burry (Eds.). Imágenes desde un alero. Investigaciones interdisciplinarias en Río Mayo, Chubut, Patagonia argentina, (pp. 33-41). Buenos Aires, Argentina: Fundación de Historia Natural Félix de Azara.

Podestá, M. M., Bellelli, C., Labarca, R., Albornoz, A. M., Vasini, A. \& Tropea, E. (2008). Arte rupestre en pasos cordilleranos del bosque andino patagónico (El Manso, Región de los Lagos y provincia de Río Negro, ChileArgentina). Magallania, 36(2), 143-153.

Prates, L., Di Prado, V., Serna, A. \& Mange, E. (2011). Cueva Galpón. Un sitio con entierros humanos y representaciones rupestres en la Sierras de Pailemán (Este de Río Negro). En F. Zangrando, R. Barberena, A. Gil y G. Neme (Eds.). Libro de Resúmenes VIII Jornadas de Arqueología de Patagonia, (p. 66). San Rafael, Argentina: Centro de Convenciones y Exposiciones Thesaurus - Museo de Historia Natural de San Rafael.

Rizzo, F. (2013). Registro funerario, uso del espacio y movilidad en el noroeste de Patagonia (provincias de Río Negro y Chubut). Primeros resultados. Relaciones de la SAA, 38(1), 137-168.

Ross, J. \& Davidson, I. (2006). Rock art and ritual: an archaeological analysis of rock art in Arid Central Australia. Journal of Archaeological Method and Theory, 13(4), 304-340.

Rumboll, M., Manzione, M. \& Blanco, C. (2011). Guía de Huellas, Rastros y Señales de los Mamíferos de los Parques Nacionales. Buenos Aires, Argentina: Administración de Parques Nacionales. Serie Pequeñas guías de Parques Nacionales 3.

Sánchez-Albornoz, N. (1958 a). Pictografías del Valle de El Bolsón (Río Negro) y del Lago Puelo (Chubut), Argentina. Acta Praehistorica, 2,146-175.

Sánchez-Albornoz, N. (1958 b). Pictografías de la pensínsula de San Pedro (Nahuel Huapi). Runa, 9(1-2), 99-106.

Schobinger, J. (1956). El Arte Rupestre de la provincia del Neuquén. Anales de Arqueología y Etnología, XII, 115-227.

Serna, A. (2014). Análisis preliminar de los restos óseos humanos del sitio Cueva Galpón (provincia de Río Negro, Argentina). En Libro de Resúmenes de las IX Jornadas de Arqueología de la Patagonia (p. 87). Coyhaique, Chile: Gobierno Nacional y su Consejo Patagonia Aysén.

Silveira, M. (1988-89). Un sitio con arte rupestre: el alero Lariviére (Provincia del Neuquén). Relaciones de la SAA, XVII, 75-86.

Tilley, C. (1991). Material Culture and Text. The Art of Ambiguity. Londres, Reino Unido: Routledge.

Troncoso, A. (2008). Arte rupestre en la cuenca del río Aconcagua: formas, sintaxis, estilo y poder. TAPA, 39, 9-243.

Vignati, M .A. (1944). Antigüedades de los lagos Nahuel Huapi y Traful. Notas del Museo de La Plata, 9(23-29), 53-165. 
Whitley, D. (2010). Art and belief: the ever changing and the never changing in the Far West. En G. Blundell, C. Chippindale y B. Smith (Eds.). Seeing and knowing. Understanding rock art with and without ethnography (pp. 116-137). Wallnut Creek, Estados
Unidos: Left Coast Press.

Whitley, D. S., Dorn, R., Simon, J., Rechtman, R. \& Whitley, T. (1999). Sally's Rockshelter and the archaeology of the vision quest. Cambridge Archaeological Journal, 9 (2), 221-247. 